\title{
Decentralisation; The Question of Management Capacity: A Response to Recent Commentaries
}

\author{
Jalal Mohammed*, Nicola North, Toni Ashton
}

\begin{abstract}
*Correspondence to: Jalal Mohammed, Email: j.mohammed@auckland.ac.nz Copyright: (c) 2017 The Author(s); Published by Kerman University of Medical Sciences. This is an open-access article distributed under the terms of the Creative Commons Attribution License (http://creativecommons.org/licenses/ by/4.0), which permits unrestricted use, distribution, and reproduction in any medium, provided the original work is properly cited.

Citation: Mohammed J, North N, Ashton T. Decentralisation; the question of management capacity: a response to recent commentaries. Int J Health Policy Manag. 2017;6(1):61-63. doi:10.15171/ijhpm.2016.134

Received: 20 September 2016; Accepted: 1 October 2016; ePublished: 4 October 2016
\end{abstract}

$\mathrm{W}$

hilst decentralisation as an instrument of healthcare reform remains popular, commentaries ${ }^{1-5}$ to our paper titled "Decentralisation of health services

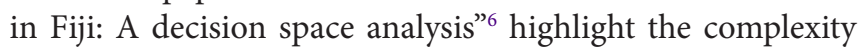
in understanding decentralisation, with the significant body of research on decentralisation lacking consensus on its definition, ${ }^{7}$ differing on what constitutes decentralisation, ${ }^{7-11}$ emphasising different theoretical underpinnings and frameworks, ${ }^{7,12-14}$ and reporting varying applications and outcomes of decentralisation. ${ }^{15}$ This is a consequence of widely varied health systems in which decentralisation has been initiated. Viewing decentralisation on a continuum, with centralisation and decentralisation on polar ends, demarcated through broad linear categories (deconcentration, delegation, devolution and privatisation $)^{12,13}$ has been useful in understanding decentralisation. However, these categories are not analytical in nature, posing problems in capturing degrees of decentralisation and for making useful comparisons. Several analytical frameworks, including the 'decision space approach ${ }^{16}$ were posited to empirically analyse decentralisation and address gaps in the decentralisation literature.

Our article, limited in scope, employed the widely applied decision space framework in understanding Fiji's decentralisation of a particular function, service delivery. Application of the decision space framework was suited to Fiji's hierarchal health system, which is inherently vertical in nature. Decentralisation initiatives may not fit neatly into analytical frameworks as illustrated in our analysis, and the use of alternative frameworks such as the arrows framework ${ }^{7}$ to examine Fiji's decentralisation initiative would increase understanding. Indeed, in a preceding study, ${ }^{17}$ we examined both decentralisation initiatives in Fiji from a functional perspective. That analysis has led to a forthcoming publication, ${ }^{18}$ where we explore some of the reasons why the current decentralisation initiative has been considered successful by the Fijian government.

In the case of Fiji, the least imposing form of decentralisation (deconcentration) was applied, entailing shifting workload from the tertiary hospital to the peripheral health centres, without a commensurate transfer of authority. There are arguments that deconcentration without a transfer of authority should not be considered decentralisation as the organisation continues to behave like a centralised system..$^{10,19}$ The decision space analysis of Fiji's decentralisation initiative supports this view, revealing a system that remains centrally controlled. The Fijian health system reflects a U Form organisation ${ }^{2}$ whereby health services are delivered through a network of government owned facilities, controlled by divisional managers who liaise with subdivisions to ensure that a minimum standardised package of health services is delivered. While this has the benefit of realising economies of scale, there is growing evidence that countries could better benefit from a mix of centralisation and decentralisation strategies, taking advantage of efficiencies gained from centralisation of certain functions and decentralisation of others., ${ }^{8,1420-22}$ In Fiji, such strategies would allow for both the efficiency of a centralised system while allowing greater flexibility in response to local communities. However, this would require substantial decentralisation (beyond deconcentration) taking hold.

In his commentary, ${ }^{5}$ Peckham noted that an examination of both vertical and horizontal relationships would better explain decision space at the decentralised health centres. We agree that horizontal relationships affect the degree of decision space and warrants further exploration in Fiji's case. In our article, we privileged the vertical relationship, as in Fijis health system relationships are mainly vertical in nature. For example, service delivery is designed to be hierarchal, with nursing stations at the lowest level and hospitals at the highest level. In Fiji, there are potential benefits to be gained from horizontal decentralisation in the area of intradivisional relationships. Our study reveals some change in horizontal relationships as a result of decentralisation. The six decentralised health centres, categorised from level C (lowest) to level A (highest), vary in the diagnostic services that they offer, resulting in sideways (horizontal) referrals from smaller to larger health centres for diagnostic services. For referrals to divisional hospitals, there is a dependent relationship between the health centre and the divisional hospital, whereby health centres have to ensure that beds are available in divisional hospitals before referring patients. If beds are not available, the patient is held at the health centre until a bed becomes 
available. However, in most respects the decentralised health centres offer limited autonomy in practitioner practice, and remain closely overseen through quarterly rotation of medical officers between the decentralised health centres. Additionally, the increased utilisation of the six health centres has meant that practitioners spend under five minutes per patient which has left little room for deviation from standard operating guidelines. ${ }^{6}$

Management capacity is considered vital to the success of decentralisation and strengthening is required at lower levels in order for decentralisation to succeed. ${ }^{12,23-25}$ However, as evident in Fijis experience, the creation of decision space may not result in increased management capacity. Fijis first decentralisation initiative was hampered by several issues, including having only three health service managers with the qualifications and experience to take on decision-making responsibilities. ${ }^{26}$ This meant decision space created at decentralised levels could not be realised, impacting not only on implementation and outcomes, but on the success of the decentralisation initiative. Therefore, whilst it is important to have an understanding of the degree of decentralisation, a measure of management capacity pre and post decentralisation would strengthen decentralisation frameworks. From a developing country perspective where resources and skills are limited, and decentralisation is used as a means to improve not only the responsiveness of health service delivery but to improve efficiencies, understanding management capacity is integral to the decentralisation process. Without management capacity, the creation of decision space may not enable the benefits of decentralisation to be realised, illustrated in Fijis case.

The debate around the effectiveness of decentralisation will continue and is unlikely to provide concrete answers for countries seeking to emulate models of successful implementation. There is no one-size-fits-all solution when it comes to decentralisation ${ }^{25}$ and indiscriminate adoption has led to negative outcomes, unintended consequences and a questioning of the benefits of decentralisation. Fijis experience reveals that countries need to follow their own path in decentralising, adapting to local environment and local needs in order to increase its chances of success. ${ }^{18}$ In spite of growing interest in analysing decentralisation, there has been less focus on understanding how decentralisation impacts major health system goals of equity, efficiency, and access. Our decision space analysis forms part of a larger study examining the impacts of decentralisation on access to healthcare in particular, through which we anticipate contributing to that understanding. Qualitative research is well-suited for gaining insights during implementation and understanding impacts on outcomes ${ }^{10}$; our qualitative study allows us to unpack the complexities of the impact of decentralisation on users' access to healthcare from the multiple and intersecting perspectives of users, healthcare workers and administrators, to be reported in future papers.

\section{Ethical issues}

Not applicable.

\section{Competing interests}

Authors declare that they have no competing interests.
Authors' contributions

$\mathrm{JM}$ drafted a plan for responding to the commentaries. TA and NN contributed to the plan. JM drafted the response. JM and NN contributed to the revisions of the response.

\section{References}

1. Bossert TJ. Decision space and capacities in the decentralization of health services in Fiji: Comment on "Decentralisation of health services in Fiji: a decision space analysis." Int $J$ Health Policy Manag. 2016;5(7):443-444. doi:10.15171/ijhpm.2016.51

2. Bustamante AV. U-form vs. M-form: how to understand decision autonomy under healthcare decentralization? Comment on "Decentralisation of health services in Fiji: a decision space analysis." Int J Health Policy Manag. 2016;5(9):561-563. doi:10.15171/ijhpm.2016.73

3. Zahmatkesh M, Exworthy M. Decentralisation, decision space and directions for future research: Comment on "Decentralisation of health services in Fiji: a decision space analysis." Int J Health Policy Manag. 2016;5(10):607-608. doi:10.15171/ijhpm.2016.76

4. Faguet JP. Low decision space means no decentralization in Fiji: Comment on "Decentralisation of health services in Fiji: a decision space analysis." Int $J$ Health Policy Manag. 2016;5(11):663-665. doi:10.15171/ijhpm.2016.82

5. Peckham S. Decentralisation-a portmanteau concept that promises much but fails to deliver? Comment on "Decentralisation of health services in Fiji: a decision space analysis." Int J Health Policy Manag. 2016;5(12):729-732. doi:10.15171/ijhpm.2016.88

6. Mohammed J, North N, Ashton T. Decentralisation of health services in Fiji: a decision space analysis. Int J Health Policy Manag. 2016;5(3):173-181. doi:10.15171/ijhpm.2015.199

7. Peckham S, Exworthy M, Powell M, Greener I. Decentralizing health services in the UK: a new conceptual framework. Public Adm. 2008;86(2):559-580.

8. Regmi K. Decentralizing Health Services: A Global Prespective. New York: Springer; 2014.

9. Saltman R. Decentralization, re-centralization and future European health policy. Eur J Public Health. 2008;18(2):104106.

10. Saltman RB, Bankauskaite V, Vrangbaek K, eds. Decentralization in Health Care: Strategies and Outcomes. Berkshire: Open University Press; 2007. European Observatory on Health Systems and Policy Series.

11. Vrangbaek K. Towards a typology for decentralization in health care. In: Saltman R, Bankauskaite V, Vrangbaek K, eds. Decentralization in Health Care: Strategies and Outcomes. Berkshire: Open University Press; 2007.

12. Mills A, Vaughan JP, Smith DL, Tabibzadeh I, eds. Health System Decentralization: Concepts, Issues and Country Experience. Geneva: World Health Organization; 1990.

13. Rondinelli D, Nellis JR, Cheema GS. Decentralization in Developing Countries: A Review of Recent Experience. Washington DC; World Bank: 1983.

14. Mitchell A, Bossert TJ. Decentralisation, governance and healthsystem performance: 'Where you stand depends on where you sit.' Dev Policy Rev. 2010;28(6):669-691. doi:10.1111/j.14677679.2010.00504.x

15. Bossert T, Mitchell A. Health sector decentralization and local decision-making: decision space, institutional capacities and accountability in Pakistan. Soc Sci Med. 2011;72(1):39-48. doi:10.1016/j.socscimed.2010.10.019

16. Bossert T. Analyzing the decentralization of health systems in developing countries: decision space, innovation and performance. Soc Sci Med. 1998;47(10):1513-1527. doi:10.1016/s0277-9536(98)00234-2

17. Mohammed J, Ashton T, North N. Wave upon wave: Fiji's experiments in decentralising its healthcare system. Asia- 
Pacific Journal of Public Health. 2016;28(3):232-243. doi:10.1177/1010539516635270

18. Mohammed J, North N, Ashton T. A context-specific approach to primary care strengthening in Fiji. In: Braithwaite J, Matsuyama Y, Mannion R, Shekelle P, Whittaker S, Al-Adawi S, eds. Health Systems Improvement Across the Globe: Success Stories From 60 Countries. 2016; Forthcoming.

19. Popic D, Patel M. Decentralization: Equity and sectoral policy implications for UNICEF in East Asia and the Pacific. Bangkok: Social Policy and Economic Analysis Unit, UNICEF EAPRO, Bangkok; 2011.

20. Conyers D. Decentralization: The latest fashion in development administration? Public Adm Dev. 1983;3(2):97-109. doi:10.1002/ pad. 4230030202

21. Elson S. Regionalization of health care from a political and structural perspective. Paper presented at: Healthcare Management Forum; 2009.
22. Berman P. Health sector reform: Making health development sustainable. Health Policy. 1995;32(1):13-28. doi:10.1016/01688510(95)00726-9

23. Mills A. Decentralization and accountability in the health sector from an international perspective: what are the choices? Public Adm Dev. 1994;14(3):281-292. doi:10.1002/pad.4230140305

24. Saide MA, Stewart DE. Decentralization and human resource management in the health sector: A case study (1996-1998) from Nampula province, Mozambique. Int J Health Plann Manage. 2001;16(2):155-168. doi:10.1002/hpm.620

25. Mosca I. Is decentralisation the real solution? A three country study. Health Policy. 2006;77(1):113-120. doi:10.1016/j. healthpol.2005.07.011

26. AUSHealth International. Fiji Health Management Reform Project Draft Annual Plan 2000-2001. Suva: AUSHealth International; 2000. 